\title{
Anticoagulation for Cerebral Venous Thrombosis with Subarachnoid Hemorrhage: A Case Report
}

\author{
Mohamed Osama Hegazi $^{a} \quad$ Sherif Ahmed ${ }^{a} \quad$ Mohamed Gaber Sakr ${ }^{b}$ \\ Omar Ahmed Hassanien ${ }^{c}$
}

Departments of a Medicine, ${ }^{b}$ Casualty and ${ }^{c}$ Radiology, Al-Adan Hospital, Kuwait

\author{
Key Words \\ Cerebral hemorrhage $\cdot$ Thrombosis $\cdot$ Subarachnoid \\ hemorrhage
}

\begin{abstract}
Objectives: To report the success of anticoagulation (AC) treatment in a case of cerebral venous thrombosis (CVT) with subarachnoid hemorrhage $(\mathrm{SAH})$ in view of the limited evidence seen in the literature supporting such a treatment option. Clinical Presentation and Intervention: A 38-year-old lady with CVT and SAH presented $12 \mathrm{~h}$ after the onset of symptoms. AC with low-molecular-weight heparin was started 4 days later, when the repeated brain CT showed regression of the SAH. Heparin was changed to warfarin, and she was asymptomatic over a 12-month follow-up period. Discussion: In a limited number of small studies, AC has been found to be beneficial for cases of CVT with hemorrhagic complications. The proper time to start $A C$ in such cases was not clearly defined, and a delay of 4-33 days was observed after the onset of symptoms. In cases of spontaneous intracranial hemorrhage $(\mathrm{ICH})$ in general, active bleeding is usually confined to the first $6 \mathrm{~h}$, and chances of hematoma enlargement are higher in the first $24 \mathrm{~h}$. On the other hand, it has been advised to rule out a coincidental vascular malformation and to radiologically confirm regression (or at least non-progression) of the ICH before starting AC. Conclusion: $A C$ for cases of CVT may remain beneficial in the presence of SAH. The time to start AC for CVT with hemorrhagic complications is unclear; however, $A C$ was successful
\end{abstract}

when given 4 days after the onset of symptoms in our case. It may be wise to repeat CT after at least $24 \mathrm{~h}$ from the onset of symptoms (to confirm regression or at least non-progression of the $\mathrm{ICH}$ ) before starting $\mathrm{AC}$. It may also be prudent to perform magnetic resonance angiography, or digital subtraction angiography to rule out a coincidental intracranial aneurysm before AC.

Copyright $\odot 2009$ S. Karger AG, Basel

\section{Introduction}

Cerebral venous thrombosis (CVT) is an increasingly recognized neurological emergency. Intracranial hemorrhages (ICH) as hemorrhagic infarctions or subarachnoid hemorrhage (SAH) complicate nearly $40 \%$ of CVT cases [1]. Treatment of CVT with anticoagulation (AC) is recommended, though the evidence for its benefit is not substantial [2]. Though AC for CVT continues to be beneficial even in the presence of ICH $[1,3,4]$, the optimum time to start such a treatment option has not been clearly defined. We report a case of CVT with $\mathrm{SAH}$, who responded favorably to AC.

\section{Case Report}

A 38-year-old woman presented with acute onset of severe diffuse headache with vomiting for the last $12 \mathrm{~h}$. She was not pregnant or puerperal, nor on contraceptive pills, and did not have any past or family history of venous thrombosis. She was fully con-

\section{KARGER}

Fax +41613061234

E-Mail karger@karger.ch

www.karger.com
(C) 2009 S. Karger AG, Basel

$1011-7571 / 10 / 0191-0073 \$ 26.00 / 0$

Accessible online at:

www.karger.com/mpp
Mohamed Osama Hegazi

PO Box 47813

64029 Fahaheel (Kuwait)

Tel. +9659740 3085, Fax +96523941638

E-Mail drosama02@gmail.com 


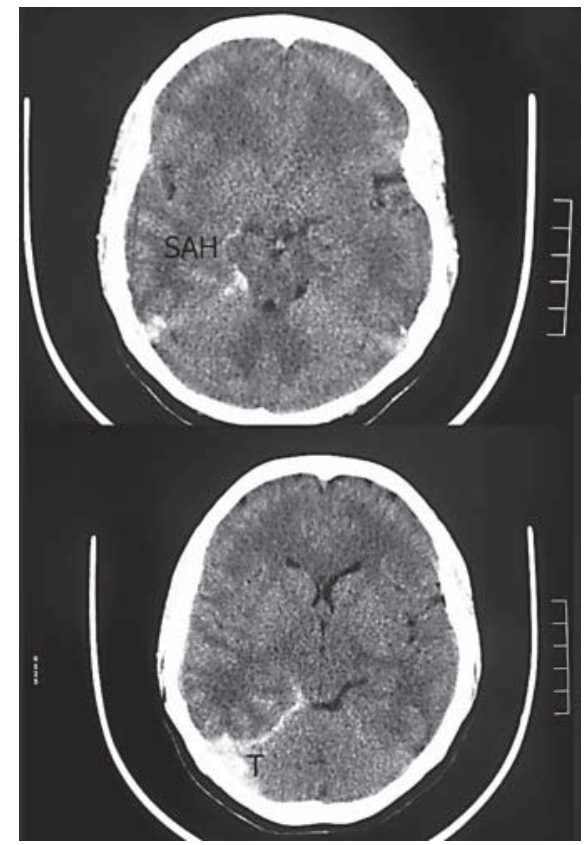

Fig. 1. Brain $\mathrm{CT}$ showing $\mathrm{SAH}$ and transverse sinus thrombosis (T).

scious, afebrile and her neck was rigid, but no focal neurological deficits could be elicited. Urgent brain CT showed evidence of CVT and SAH (fig. 1). Laboratory workup showed normal full blood count, normal renal, hepatic and coagulation profiles, and negative antiphospholipid antibodies. Tests for plasma fibrinogen, protein $C$, protein $S$, activated protein $C$ resistance and antithrombin-III were normal. Checking for the prothrombin gene mutation (G20210A) was not carried out; however, this type of thrombophilia is extremely rare in individuals of Asian descent, like our patient [5]. Treatment with analgesia and mannitol was started, and the patient was closely observed. Brain magnetic resonance angiography with venography confirmed superior sagittal and right transverse sinus thromboses, and was negative for vascular malformations (fig. 2). AC with low-molecular-weight heparin (enoxaparin $1 \mathrm{mg} / \mathrm{kg}$ twice daily) was started 4 days after the onset of symptoms, and when repeated CT showed that SAH had regressed. The patient's symptoms disappeared, and she had an uneventful course thereafter. Heparin was changed to warfarin, and she was asymptomatic over a 12-month follow-up period.

\section{Discussion}

CVT is an uncommon serious neurological emergency that is being increasingly diagnosed due to better clinical awareness and improved imaging techniques. Prothrombotic risk factors, infections and Behcet's disease are among the most frequently identified causes [2]. Pre-

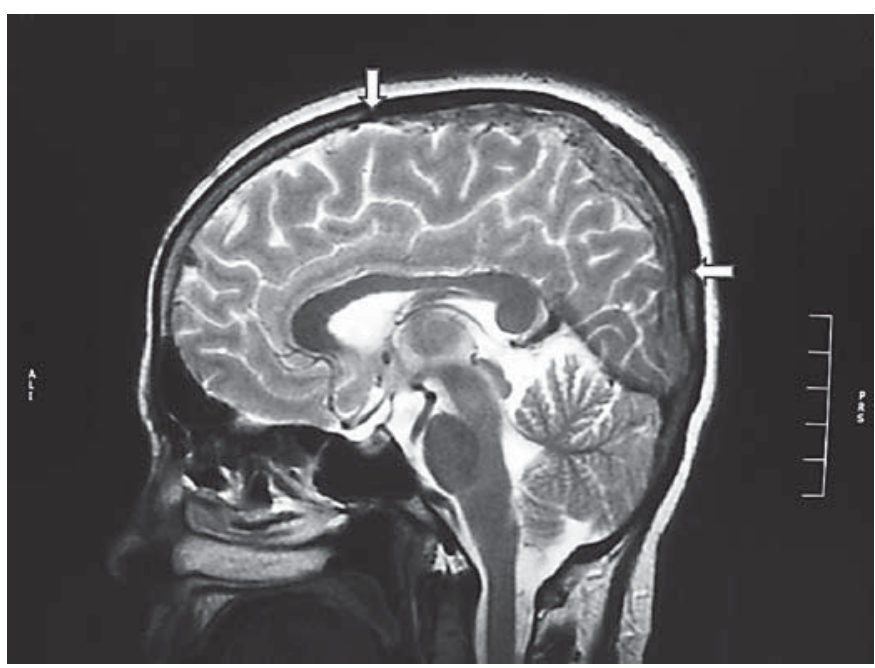

Fig. 2. Brain magnetic resonance angiography with venography showing superior sagittal sinus thrombosis (between arrows).

senting symptoms and signs include headache, epilepsy, focal neurological deficits and impairment of consciousness [2]. The priority of treatment in the acute stage should be to stabilize the patient's condition and to prevent or reverse cerebral herniation [2].

Although there is no substantial evidence-based consensus that $\mathrm{AC}$ is beneficial in CVT, most neurologists currently start treatment with heparin as soon as the diagnosis is confirmed, even in the presence of hemorrhagic complications [2]. Heparin treatment has been shown to be beneficial rather than hazardous when CVT is associated with ICH $[1,3,4]$. Of 43 patients with CVT and ICH, Einhäupl et al. [1] reported a mortality of $15 \%$ in heparin-treated patients compared to $69 \%$ that in those who did not receive heparin. Of 29 patients with ICH and CVT who were treated with low-molecular-weight heparin, de Bruijn and Stam [3] reported 6 deaths, but none of them could be attributed to new or enlarged cerebral hemorrhage. In our case, AC therapy was associated with a favorable outcome, bearing in mind it was started 4 days after the onset of symptoms and after confirming that SAH had regressed. An important point is the safety of immediate AC with cases of SAH and CVT upon presentation. This point needs further clarification as in most of the reported cases of CVT with $\mathrm{ICH}$, heparin treatment was delayed $[1,3,6,7]$. Wingerchuk et al. [6] stated 
that AC was safely initiated within several days in clinically stable patients with non-temporal-lobe hemorrhagic infarcts of unchanging volume, and highlighted that the location and unchanged volume on serial CT may be important factors influencing the safety of AC therapy in patients with CVT and hemorrhagic infarcts. Oppenheim et al. [7] suggested performing magnetic resonance angiography, or preferably digital subtraction angiography, to rule out intracranial aneurysm before AC in cases of CVT with SAH. In the study by Einhäupl et al. [1], mean delay between the onset of symptoms and heparin treatment was 33 days; in the study of Bruijn and Stam [3], this was 10.6 days. No studies were found to evaluate the time interval when enlargement of venous intracerebral hemorrhages is more likely to occur; however, in general, active bleeding into the brain is usually confined to the first $6 \mathrm{~h}$ following $\mathrm{ICH}$, with $10-15 \%$ of patients showing hematoma enlargement between 6 and $24 \mathrm{~h}$ from the onset of spontaneous ICH [8].

\section{Conclusion}

AC treatment for cases of CVT with hemorrhagic complications was not associated with adverse outcome. However, if ICH is present, immediate AC for CVT at presentation and within $24 \mathrm{~h}$ from onset of symptoms cannot be safely recommended, as in almost all previous reports there was a delay in the onset of $\mathrm{AC}$ ranging between 4 and 33 days. Although there is no known definite waiting period, repeating CT after at least 1 day from onset of symptoms to confirm that ICH is regressing or at least not progressing may be advisable before starting AC. It may also be prudent to perform magnetic resonance angiography or digital subtraction angiography before AC in cases of CVT with SAH to rule out a coincident intracranial aneurysm.

\section{References}

1 Einhäupl KM, Villringer A, Meister W, Mehraein S, Garner C, Pellkofer M, Haberl RL, Pfister HW, Schmiedek P: Heparin treatment in sinus venous thrombosis. Lancet 1991;338:597-600.

2 Stam J: Thrombosis of the cerebral veins and sinuses. N Engl J Med 2005;352:1791-1798.

3 de Bruijn SF, Stam J: Randomized, placebocontrolled trial of anticoagulant treatment with low-molecular-weight heparin for cerebral sinus thrombosis. Stroke 1999;30:484488.
4 FinkJN, McAuley DL: Safety of anticoagulation for cerebral venous thrombosis associated with intracerebral hematoma. Neurology 2001;57:1138-1139.

-5 Rosendaal FR, Doggen CJ, Zivelin A, Arruda VR, Aiach M, Siscovick DS, Hillarp A, Watzke HH, Bernardi F, Cumming AM, Preston FE, Reitsma PH: Geographic distribution of the $20210 \mathrm{G}$ to A prothrombin variant. Thromb Haemost 1998;79:706-708.

-6 Wingerchuk DM, Wijdicks EF, Fulgham JR: Cerebral venous thrombosis complicated by hemorrhagic infarction: factors affecting the initiation and safety of anticoagulation. Cerebrovasc Dis 1998;8:25-30.
7 Oppenheim C, Domigo V, Gauvrit JY, Lamy C, Mackowiak-Cordoliani MA, Pruvo JP, Méder JF: Subarachnoid hemorrhage as the initial presentation of dural sinus thrombosis. AJNR Am J Neuroradiol 2005;26:614617.

$>8$ Fujii $\mathrm{Y}$, Tanaka R, Takeuchi S; Koike T, Minakawa T, Sasaki O: Hematoma enlargement in spontaneous intracerebral hemorrhage. J Neurosurg 1994;80:51-57. 